\title{
DIREITO À MORADIA E OS BENEFÍCIOS DE UMA POLÍTICA DE ACOLHIMENTO PERMANENTE PARA AS PESSOAS EM SITUAÇÃO DE RUA
}

\author{
http://dx.doi.org/10.21527/2176-6622.2021.55.173-187
}

Recebido em: 23/3/2020

Modificações solicitadas em: 26/6/2020

Aceito em: 21/7/2020

\section{Luiz Sales do Nascimento}

Autor correspondente. Universidade Católica de Santos - Unisantos. Av. Conselheiro Nébias, 589/595 - Boqueirão. CEP 11045-003. Santos/SP, Brasil. http://lattes.cnpq.br/5585248986676203. https://orcid.org/0000-0001-6854-4539. luiz.sales@unisantos.br

\section{Carlos Gustavo Guimarães Albergaria Barreto}

Universidade Católica de Santos - Unisantos. Santos/SP, Brasil.

\section{RESUMO}

Este artigo objetivou identificar os benefícios e dificuldades relacionados ao acolhimento permanente de pessoas em situação de rua, verificando-se a real possibilidade de se adotar tal sistemática no Brasil. Para compor o estudo, utilizou-se metodologia hipotético-dedutiva no tocante ao impacto da referida política pública na vida dos indivíduos beneficiados, seguida de método comparativo no âmbito do acolhimento permanente em outros Estados. Conclui-se que, no caso do Brasil, dentre os inúmeros modelos adotados pelo mundo, o modelo de acolhimento permanente que mais se adequa às nossas peculiaridades é o Communal Housing First (CHF), por conciliar baixo custo fiscal com eficiência na alocação de serviços públicos.

Palavras-chave: Pessoas em situação de rua. Direitos humanos. Moradia primeiro.

\section{RIGHT TO HOUSING AND THE BENEFITS OF A PERMANENT RECEPTION POLICY FOR HOMELESS PEOPLE}

\section{ABSTRACT}

This article aimed to identify the benefits and difficulties related to the permanent reception of people living on the street, verifying the real possibility of adopting such a system in Brazil. To compose the analysis, we used the hypothetical-deductive methodology concerning the impact of the aforementioned public policy on the lives of the beneficiaries, followed by a comparative method within the scope of permanent reception in other States. It is concluded that the case of Brazil, among the countless models adopted by the World, the permanent reception model that best suits our peculiarities is the CHF (Communal Housing First), for reconciling low fiscal cost with efficiency in the allocation of public services.

Keywords: Homeless People. Human Rights. Housing First.

\section{SUMÁRIO}

1 Introdução. 2 Direito à moradia adequada. 2.1 Direito humano e fundamental. 2.1.1 Declaração Universal dos Direitos do Homem (DUDH), outros instrumentos normativos internacionais e a Agenda 2030. 2.1.2 Direito interno. Constituição Federal e Emenda Constitucional (EC) no 26/2000. 3 Pessoas em situação de rua. 3.1 Conceito e Políticas Públicas. 3.2 Política atual: assistência social e benefícios eventuais, o Aluguel Social e suas limitações e os Centros de Referência Especializados para População em Situação de Rua - Centros POP. 4 Acolhimento permanente: benefícios e perspectivas. 4.1 Experiências internacionais. Housing First. 4.2 Reintegração social e comunitária facilitada. 4.3 Segurança habitacional para pessoas em situação de rua e uma proposta para o Brasil. 5 Conclusão. 6 Referências. 


\section{INTRODUÇÃO}

O Direito à moradia adequada constitui um direito humano e fundamental de salutar importância, por viabilizar o próprio exercício digno dos demais direitos. Nesse contexto, viabilizar o efetivo exercício de tal direito, introduzindo as políticas públicas necessárias a efetivar a disponibilização de moradia a todos, constitui uma das principais aspirações dos gestores contemporâneos.

Se o deficit habitacional para atender à crescente demanda já constitui grave problema e enorme desafio, ele potencializa-se ainda mais quando se trata do direito à moradia das pessoas em situação de rua. Independentemente dos fatores que levaram esses indivíduos a habitar praças e logradouros públicos (problemas mentais, desemprego, desestruturação familiar, vício em entorpecentes, alcoolismo, etc.), sua vulnerabilidade social potencializa o menoscabo a seus direitos mínimos e essenciais.

Sujeitos às intempéries e aos maus tratos, esses indivíduos contam com uma rede de proteção, desenvolvida recentemente, que prima pela reinserção progressiva dessas pessoas no ambiente social, com etapas transitórias e definidas, com uma fase inicial de acolhimento em abrigos e em casas de reabilitação. Em que pese o êxito relativo de tal sistemática, a curta duração da adaptação traz como efeito nocivo o retorno à situação de rua.

Como observa-se na introdução supra e em relação aos problemas expostos, parece-nos relevante investigar: Essa sistemática de reintrodução paulatina do indivíduo constitui a melhor abordagem para solucionar o problema dos moradores em situação de rua? A efetiva e imediata cessão de um lar a uma pessoa em situação de rua - invertendo-se o processo usual de reabilitação - possibilita uma integração mais efetiva e de longo prazo do indivíduo? A experiência conhecida por housing first, desenvolvida por Sam Tsemberis nos EUA há algumas décadas, poderia ser importada para o Brasil? São essas as diretivas que serão postas à prova no desenvolvimento desta breve pesquisa.

O objetivo geral do presente artigo é contribuir para uma melhor compreensão do tema, abordando-o de forma abrangente, uma vez que ainda há poucos estudos específicos de campo em nosso país para se aquilatar o efetivo impacto da nova sistemática nas relações sociais, embora se possa antecipar que sua efetivação seria extremamente relevante para a comunidade de uma forma geral, por resgatar, de maneira mais efetiva e duradoura, cidadãos que atualmente constituem um ônus social e financeiro, reinserindo-os na rede social produtiva e iterativa. De modo mais individualizado, a abordagem prima pela concessão de uma habitação antes mesmo de se iniciar a recuperação física/emocional/psicológica desses indivíduos, resgatando-os de uma vulnerabilidade extrema e thes concedendo mais que um teto - uma morada.

O objetivo específico é demonstrar sua potencial utilidade na pioneira abordagem na recuperação/ressocialização das pessoas em situação de rua, verificando-se a real possibilidade de se adotar tal sistemática em nosso país a partir da análise de experiências bem-sucedidas ocorridas em outros países.

Em termos metodológicos, parece-nos coerente, com base na argumentação supra, abordar o tema sob uma metodologia hipotético-dedutiva no tocante ao impacto da referida política pública na vida dos indivíduos beneficiados, uma vez que ainda são escassos os dados empíricos para possibilitar um diagnóstico mais preciso (ao menos em nosso país), enquanto a análise dos resultados obtidos em outros Estados e a possibilidade de sua reprodução internamente, reclamam uma metodologia sistêmica e comparativa.

Utilizaremos, ainda, a pesquisa analítica do objeto, avaliando, com maior profundidade, os dados, explicando intuitivamente o contexto do objeto no âmbito interno e seu pretenso impacto sobre a população em situação de rua.

\section{DIREITO À MORADIA ADEQUADA}

O direito à moradia constitui uma necessidade básica do indivíduo, um pressuposto basilar ao completo desenvolvimento do ser humano, assegurando-se sua intrínseca dignidade. Não se trata apenas de se assegurar um abrigo, mas, sim, um lar, um ambiente que vai além de uma estrutura física adequada para permitir um completo desenvolvimento do indivíduo. 
Não é por outro motivo que o Comitê dos Direitos Econômicos, Sociais e Culturais das Nações Unidas salienta que o Direito à Moradia adequada pressupõe o direito de morar em paz, em segurança e com dignidade (OFFICE OF THE UNITED NATIONS..., 2014, p. 3).

O reconhecimento do direito à moradia adequada relaciona-se com a noção de mínimo existencial, decorrência lógica e inafastável da dignidade da pessoa humana (artigo 1으, III, CF). Como suprarreferido, não se trata apenas de disponibilizar uma habitação, um alojamento, um abrigo das intempéries, mas, sim, uma estrutura adequada, que seja digna, possibilitando qualidade de vida dotada de condições compatíveis de higiene e conforto, preservando a intimidade pessoal e a privacidade familiar (RANGEL, 2009, p. 57-78).

Nolasco (2018) conceitua o direito à moradia como a posse exclusiva, durante um razoável período de tempo, de espaço determinado no qual se tenha proteção contra intempéries, assegurando-se a intimidade do indivíduo, além da possibilidade de prática dos atos elementares da vida humana, como alimentação, repouso, higiene, reprodução e comunhão. Logo, o direito à moradia não apenas propicia dignidade, como ele mesmo decorre da dignidade da pessoa humana, em relação simbiótica e indissociável, uma vez que é no conforto e segurança do lar que muitos dos direitos humanos florescem.

Inicialmente, poder-se-ia associar a ideia de habitação à propriedade, o que parece até intuitivo, posto que o domínio de uma unidade habitacional propicia o efetivo exercício do direito à habitação. Não se trata, contudo, propriamente de uma decorrência lógica do direito à propriedade (embora haja uma correlação evidente, como apontado anteriormente), uma vez que o direito à moradia não pressupõe moradia própria, mas moradia adequada e digna (NOLASCO, 2018).

Nesse sentido, nem sempre a moradia própria (propriedade ou domínio) reúne os atributos que se lhe qualificam como morada digna (basta se imaginar as condições insalubres de favelas, palafitas, dentre outros exemplos).

Em verdade, em alguns casos o direito à moradia sujeita o próprio direito à propriedade. Sarlet (1988), inclusive, destaca alguns julgados de cortes estrangeiras e nacionais em que o direito à moradia sobrepujou o direito à propriedade.

Trata-se de um direito social (de 2 a geração, portanto, prestacional, programático). Tais direitos nasceram a partir do início do século 20, inseridos no constitucionalismo do Estado Social (welfare state), fruto de um movimento antiliberal, uma contraposição ao dominante laissez-faire (MAZZUOLI, 2017). Ademais, para se adequar aos modernos ditames de dignidade, não basta configurar um teto, e sim uma proteção ampla. Nesse sentido é que se aduz a habitação adequada.

Em relação à ideia de adequação, é salutar referir-se às profícuas conclusões do Comitê sobre os Direitos Econômicos, Sociais e Culturais ao elaborar o Comentário Geral oo 4 (UNITED NATIONS, 1991), elencando os 7 fatores que caracterizam a adequação habitacional, quais sejam: 1) segurança legal da posse, consistente na segurança jurídica contra despejos forçados ou pressões incômodas para desocupação; 2) disponibilidade de serviços, materiais, facilidades e infraestrutura, como sendo acesso sustentável a recursos naturais e comuns (energia elétrica, água potável) e infraestrutura (serviços de emergência, saneamento básico, armazenagem de alimentos, armazenagem de resíduos sólidos); 3) custo acessível, inclusive com atuação efetiva dos Estados, por meio de subsídios habitacionais e proteção contra especulação e aumentos abusivos do valor de locações, além de propiciar oferta adequada de materiais de construção; 4) habitabilidade, como sendo proteção efetiva contra intempéries (frio, umidade, calor, chuva, vento, etc.), além de prevenção contra ameaças à saúde e riscos estruturais, uma vez que a habitação inadequada ou insalubre, enquanto fator ambiental, é determinante para a fixação de altas taxas de mortalidade e morbidade em análises epidemiológicas; 5) acessibilidade, referente à facilitação de acesso dos grupos mais sensíveis e hipossuficientes à moradia (crianças, enfermos, idoso, portadores de doenças graves, etc.), priorizando-se políticas públicas que busquem tais objetivos; 6) localização, tanto referente à proximidade de serviços públicos essenciais e opções de trabalho e lazer, como também evitando-se edificações em áreas poluídas; e 7) adequação cultural, ou seja, o conjunto arquitetônico deve espelhar a identidade e diversidade cultural dos habitantes. 
Como percebe-se nos inúmeros e relevantes fatores elencados, não basta a disponibilidade de um abrigo, mas uma morada adequada e permanente, dotada de infraestrutura completa, com um custo acessível, que viabilize proteção física a seus habitantes, disponibilizada amplamente (com especial atenção para os grupos vulneráveis), localizada próxima ao centro de atividade dos indivíduos e edificada respeitando a diversidade cultural de cada grupo social.

\subsection{Direito Humano e Fundamental}

Inicialmente, parece-nos salutar aduzir que adotamos a corrente doutrinária que defende uma diferenciação entre os termos "direito humano" e "direito fundamental", consignando-se que o direito fundamental nada mais é que um direito humano positivado na carta constitucional de um Estado (RAMOS, 2018, p. 53).

Aliás, registre-se a perfeita técnica do constituinte de 1988 ao utilizar tal distinção conceitual com admirável zelo técnico. $O$ direito à moradia, nesse contexto, tanto figura no rol de direitos humanos quanto no de direitos fundamentais.

\subsubsection{Declaração Universal dos Direitos do Homem (DUDH), outros instrumentos normativos internacionais e a Agenda 2030}

Há uma série de instrumentos normativos internacionais que preveem o direito à moradia como um direito básico humano, sejam instrumentos genéricos, destinados indistintamente a toda coletividade, sejam instrumentos individualizados, fruto da especificação (passagem gradual para determinação dos sujeitos titulares de direitos), seja em relação ao gênero, à fase da vida ou de estados normais/excepcionais, como ensina Bobbio (2004, p. 46-61).

De plano, é fundamental notar que tal direito figura no mais importante instrumento normativo disciplinador dos direitos humanos. A DUDH, de 1948, elenca especificamente o direito à moradia como um direito humano universal, ao registrar, em seu artigo 25 , que

Todo ser humano tem direito a um padrão de vida capaz de assegurar-lhe, e a sua família, saúde e bem-estar, inclusive alimentação, vestuário, habitação, cuidados médicos e os serviços sociais indispensáveis, e direito à segurança em caso de desemprego, doença, invalidez, viuvez, velhice ou outros casos de perda dos meios de subsistência em circunstâncias fora de seu controle.

Além da DUDH, o direito à moradia figura no artigo 11 do Pacto Internacional dos Direitos Econômicos, Sociais e Culturais:

Os Estados Partes no presente Pacto reconhecem o direito de todas as pessoas a um nível de vida suficiente para si e para as suas famílias, incluindo alimentação, vestuário e alojamento suficientes, bem como a um meIhoramento constante das suas condições de existência. Os Estados Partes tomarão medidas apropriadas destinadas a assegurar a realização deste direito reconhecendo para este efeito a importância essencial de uma cooperação internacional livremente consentida (BRASIL, 1992, Artigo11).

Em atenção à especificação, há referência do direito à habitação no artigo 11 da Convenção sobre a Eliminação de Todas as Formas de Discriminação contra a Mulher, de 1979 (Dec. № 4377/02:

2. Os Estados-Partes adotarão todas as medias apropriadas para eliminar a discriminação contra a mulher nas zonas rurais a fim de assegurar, em condições de igualdade entre homens e mulheres, que elas participem no desenvolvimento rural e dele se beneficiem, e em particular as segurar-Ihes-ão o direito a: (...) h) gozar de condições de vida adequadas, particularmente nas esferas da habitação, dos serviços sanitários, da eletricidade e do abastecimento de água, do transporte e das comunicações (BRASIL, 1984, artigo 11).

Há previsão, no artigo 27 da Convenção sobre os Direitos da Criança (Dec. no 99.710/90), que:

3. Os Estados Partes, de acordo com as condições nacionais e dentro de suas possibilidades, adotarão medidas apropriadas a fim de ajudar os pais e outras pessoas responsáveis pela criança a tornar efetivo esse direito e, caso necessário, proporcionarão assistência material e programas de apoio, especialmente no que diz respeito à nutrição, ao vestuário e à habitação (BRASIL, 1990, artigo 27). 
Há previsão, igualmente, no artigo 21 da Convenção relativa ao Estatuto dos Refugiados (Dec. no $50.215 / 61)$, que,

No que concerne ao alojamento, os Estados Contratantes darão, na medida em que esta questão seja regulada por leis ou regulamentos ou seja submetida ao controle das autoridades públicas, aos refugiados que residam regularmente no seu território, tratamento tão favorável quanto possível e, em todo caso, tratamento não menos favorável do que aquele que é dado, nas mesmas circunstâncias, aos estrangeiros em geral (BRASIL, 1961, Artigo 21).

Também há previsão no artigo 43 da Convenção Internacional sobre a Proteção dos Direitos de Todos os Trabalhadores Migrantes e dos Membros das suas Famílias:

1. Os trabalhadores migrantes beneficiam de tratamento igual ao que é concedido aos nacionais do Estado de emprego em matéria de: (...) d) Acesso à habitação, incluindo os programas de habitação social, e proteção contra a exploração em matéria de arrendamento; (...) 3. Os Estados de emprego não devem impedir que os empregadores de trabalhadores migrantes Ihes disponibilizem habitação ou serviços culturais ou sociais. Sem prejuízo do disposto no artigo 70ㅇ da presente Convenção, um Estado de emprego pode subordinar o estabelecimento dos referidos serviços às condições geralmente aplicadas no seu território nesse domínio (BRASIL, 1990, artigo 43).

Por fim, há previsão no artigo 28 da Convenção Internacional sobre os Direitos das Pessoas com Deficiência (Dec. 6949/09), internalizado pelo rito previsto no artigo 5으, § 3으, CF, integrando atualmente o bloco de constitucionalidade pátrio:

1. Os Estados Partes reconhecem o direito das pessoas com deficiência a um padrão adequado de vida para si e para suas famílias, inclusive alimentação, vestuário e moradia adequados, bem como à melhoria contínua de suas condições de vida, e tomarão as providências necessárias para salvaguardar e promover a realização desse direito sem discriminação baseada na deficiência.

2. Os Estados Partes reconhecem o direito das pessoas com deficiência à proteção social e ao exercício desse direito sem discriminação baseada na deficiência, e tomarão as medidas apropriadas para salvaguardar e promover a realização desse direito, tais como: (...) d) Assegurar o acesso de pessoas com deficiência a programas habitacionais públicos (BRASIL, 2009, artigo 28).

Logo, o direito internacional dos direitos humanos reconhece largamente o referido direito, demonstrando sua inequívoca importância. Ilustrando essa importância, cumpre-nos destacar que o item 11.1 da Agenda 2030 da ONU para o desenvolvimento sustentável registra: "11.1 Até 2030, garantir o acesso de todos à habitação segura, adequada e a preço acessível, e aos serviços básicos e urbanizar as favelas" (ONU, 2015, Objetivo 11).

Destarte, além de uma ampla enunciação e reconhecimento histórico em inúmeros dispositivos, o direito à habitação adequada figura como aspiração social da humanidade, atenta ao desenvolvimento sustentável e ao combate às mazelas que afligem nossa sociedade.

\subsubsection{Direito interno. Constituição Federal e Emenda Constitucional (EC) no 26/2000}

Internamente, a inclusão específica do direito social fundamental à moradia é bem mais recente. 0 Poder Constituinte, originário de 1988, não incluiu em seu rol de direitos sociais especificamente o direito à moradia, embora haja inúmeros dispositivos esparsos que tratem indiretamente do tema (artigo 21, XX; artigo 23, IX; artigos 182 e 183, etc.).

Apenas em 1996, por meio de Proposta de Emenda Constitucional (PEC) de autoria do senador Mauro Miranda (PMDB/GO), apresentada no Senado e, posteriormente, remetida à Câmara dos Deputados (no qual tramitou sob o no 601/1998), é que se discutiu sua inclusão no texto constitucional, culminando com a aprovação da EC no 26/2000, que alterou a redação do artigo 60 da CF, incluindo o direito à moradia dentre o rol de direitos fundamentais sociais. Tal iniciativa decorreu de situação pitoresca, como se infere da justificativa que acompanhou a PEC. 
O Brasil participou da Conferência Habitat II, convocada pela ONU e realizada entre 3 e 14 de junho de 1996 em Istambul, Turquia, tendo sido indicado para relatar a parte da Agenda do Habitat que tratava do direito à moradia. Na ocasião, percebeu-se que nossa Carta Política de 88 não reconhecia em seu rol de direitos fundamentais o direito à habitação como um direito social, o que precipitou a proposta de PEC, redigida apenas e tão somente para incluir o direito à moradia no rol do artigo 6ㅇ da Constituição Federal.

Em verdade, há longa data existia uma preocupação da Comunidade Internacional com o direito à habitação, já reconhecido na DUDH, como anteriormente referido, além da positivação em inúmeros outros instrumentos, independentemente de sua denominação (habitação ou alojamento).

Desde a realização da 1a Conferência das Nações Unidas sobre Assentamentos Humanos (Habitat I), realizada no Canadá, em 1976, quando se discutiu a questão humanitária, que a moradia adequada e os serviços a ela inerentes são tratados como direito humano básico referente aos refugiados. Assim, é salutar a iniciativa, conferindo status constitucional a importantíssimo direito social, seja por questões humanas, seja por necessidades humanitárias.

\section{PESSOAS EM SITUAÇÃO DE RUA}

\subsection{Conceito e Políticas Públicas}

Considerando a importância atribuída ao direito à moradia, resta evidente que seu desrespeito vitima gravemente o indivíduo, privando-o de um dos mais básicos elementos qualificadores de sua dignidade.

Conforme definição normativa do artigo 1ㅇ, parágrafo único, do Decreto no 7.053/09, tal segmento (população em situação de rua) constitui

Grupo populacional heterogêneo que possui em comum a pobreza extrema, os vínculos familiares interrompidos ou fragilizados e a inexistência de moradia convencional regular, e que utiliza os logradouros públicos e as áreas degradadas como espaço de moradia e de sustento, de forma temporária ou permanente, bem como as unidades de acolhimento para pernoite temporário ou como moradia provisória (BRASIL, 2009, artigo $1^{\circ}$ ).

Como pode-se perceber pela definição normativa, trata-se de segmento populacional fragilizado, sujeito à nefasta vulnerabilidade social.

Observa-se, inclusive, que a denominação adotada (pessoa em situação de rua) objetiva exatamente dissociar tal condição do estado fixo da pessoa, sendo tratada como um processo, uma situação momentânea, que se pretende superar (JUNIOR, 2016, p. 231).

Aliás, além da privação do abrigo físico em si, a ausência de moradia permanente e adequada priva esses indivíduos do gozo dos demais direitos sociais (saúde, educação, alimentação, etc.), uma vez que há dificuldade em monitorar a localização e as condições pessoais desses indivíduos, inviabilizando uma política prestacional mais efetiva e eficiente, até pela heterogeneidade que caracteriza tal parcela populacional.

Atento à precariedade da situação desse segmento, fora instituída, em 2009, por meio do Decreto no 7.053, a Política Nacional para a População em Situação de Rua.

Trata-se de instrumento normativo de suma importância, que sintetizou os anseios e perspectivas de iniciativas públicas e privadas anteriores (tardias, é verdade), a exemplo do I Encontro Nacional sobre a População em Situação de Rua, de 2005, por meio dos quais as autoridades públicas e segmentos participativos da sociedade civil compreenderam a necessidade de viabilizar a instituição de políticas públicas direcionadas para mitigar os efeitos da vulnerabilidade social que acomete um número crescente da população.

O referido Decreto elenca os princípios, diretrizes e objetivos que norteiam as políticas públicas voltadas à população em situação de rua, além de instituir o Comitê Intersetorial de Acompanhamento e Monitoramento da referida política pública. A simples leitura do documento demonstra sincera preocupação dos atores sociais com a situação calamitosa do processo de rualização.

Como aponta Bobbio, contudo, a enumeração de direitos constitui etapa simplória e facilitada, posto que a verdadeira dificuldade, o real desafio, é estabelecer tais direitos. 
Nesse aspecto, há uma vontade crescente nos últimos anos, tanto por parte das autoridades constituídas quanto da sociedade civil, de efetivar tais políticas com o reconhecimento e o pleno exercício dos direitos sociais pelos indivíduos fragilizados, sendo o acesso à moradia adequada a primeira etapa de tal proceder.

Aliás, as autoridades internacionais estão atentas a eventuais abusos por parte dos Estados. Em junho de 2018 a Rapporteur especial do Conselho de Direitos Humanos da ONU para moradia adequada, Leilani Farha, publicou uma Carta Aberta dirigida à Hungria, denunciando uma emenda legislativa em curso que pretendia alterar a lei fundamental daquele estado para criminalizar a moradia de rua (FARHA, 2018), quando a Hungria já registrava 50 mil pessoas nessa situação. Em que pese a preocupação, não há internamente, de fato, uma política efetiva para debelar a situação.

Inicialmente, a própria definição da efetiva população em situação de rua é complicada, uma vez que a rotatividade e heterogeneidade são características desse grupo populacional, cuja própria definição normativa suprarreferida é criticada por dar ênfase à ausência de vínculos familiares e de moradia convencional, ancorado na tríade valorativa família-casa-trabalho, sem pôr em relevo o alijamento dos direitos fundamentais de tais indivíduos (SILVA, 2015, p. 121).

Não há, também, dados precisos (até pelas dificuldades narradas anteriormente). Estima-se que em 2015 existiam pouco mais de cem mil pessoas em situação de rua no Brasil (NATALINO, 2016, p. 24).

Os abrigos existentes são insuficientes. Na cidade do Rio de Janeiro, por exemplo, havia, em 2016, 2.115 vagas nos 62 abrigos do município, enquanto se estimava uma população em situação de rua na capital fluminense de cerca de 14,2 mil pessoas (VILELA, 2017); um aumento de mais de $150 \%$ nos últimos três anos.

Observa-se, portanto, que a População em Situação de Rua (PSR) constitui um segmento crescente da população, sujeito à grave vulnerabilidade social, que exige dos atores sociais medidas efetivas para estabelecimento das políticas públicas previstas no Plano Nacional, que completará, em dezembro, dez anos de vigência.

\subsection{Política atual: assistência social e benefícios eventuais, o Aluguel Social e suas limitações e os Centros de Referência Especializados para População em Situação de Rua - Centros POP}

Após as considerações introdutórias anteriores, apresentando e contextualizando o problema, cumpre-nos tratar de aspecto mais relevante para a mitigação do problema social, qual seja, uma política efetiva de acolhimento de tais indivíduos, mitigando os graves efeitos decorrentes da ausência de moradia (digna e adequada).

De plano, há que se anotar, como já comentado, que o Brasil possui um crescente deficit habitacional. Segundo dados da Pesquisa Nacional por Amostra de Domicílios (Pnad) do IBGE, de 2015, havia um deficit da ordem de 6.186.503 de domicílios (CBIC, 2019).

Atualmente, esse número orbita na casa de 7,757 milhões de moradias, segundo a Fundação Getulio Vargas (FGV) (VILAS BOAS; CONCEIÇÃO, 2019). Logo, se a falta de moradia adequada já é um grave problema para os indivíduos regularmente inseridos no tecido social, para aqueles marginalizados em situação de rua a problemática é ainda mais desesperadora.

Os dados mais recentes do Instituto de Pesquisas Econômicas Aplicadas (Ipea) mostram que a população estimada em situação de rua em 2015 somava cerca de 101.854 indivíduos, como referido anteriormente, cuja grande maioria $(77,02 \%)$ habitam municípios de grande porte, de mais de cem mil habitantes (IPEA, 2017). Assim, cumpre-nos, inicialmente, referir os institutos mais relevantes dos chamados staircases de acomodação das pessoas sujeitas à vulnerabilidade social.

A atuação do Poder Público na criação de políticas para combater a situação de vulnerabilidade que enfrentam os indivíduos em situação de rua principia por atacar os aspectos mais imediatos do problema. Quando o risco social é temporário e emergencial, usualmente recorre-se à rede assistencial, com a concessão de aluguel social.

O aluguel social é benefício assistencial eventual temporário, idealizado para atender necessidades transitórias advindas da remoção de indivíduos domiciliados em áreas de risco, desabrigados em razão de vulnerabilidade momentânea decorrente de calamidade pública. Nesse sentido, o artigo 8으, do Decreto no $6307 / 07$, regulamentou o artigo 22, § $2^{\circ}$, da Loas (Lei $n=8742 / 93$ ), que trata do estabelecimento de benefícios eventuais para atendimento de necessidades humanas advindas de vulnerabilidade temporária (BRASIL, 2007, artigo 22). 
Em que pese exigir a regulamentação e a fiscalização municipal, trata-se, como regra, de valores mensais destinados a famílias vitimadas por calamidades públicas que se encontram desabrigadas. Como pode-se perceber, além da especificidade (vítimas de calamidade pública), o benefício é temporário, não se prestando propriamente à regularização da situação habitacional das pessoas em situação de rua, uma vez que visa a apenas debelar uma situação momentânea, um risco social temporário.

Já os Centros de Referência Especializados para População em Situação de Rua (Centro POP), decorrentes da prestação de serviços prevista no artigo 23 , II, da Lei $n=8.742 / 93$, e regulamentado pelo Decreto $n$ o 7.053/09, apenas se destinam à prestação de serviços médicos e assistenciais.

Observe-se que há a previsão normativa de acolhimento temporário (abrigos) prevista no artigo 8o do Decreto $n$ 0 7.053/09, mas não há uma política de acolhimento permanente para tais indivíduos dentre os objetivos encartados no artigo 70 do referido Decreto. Aliás, sequer a articulação integrada fora mantida, uma vez que a política (equivocada) de estado Mínimo do governo atual revogou o Comitê Intersetorial previsto para acompanhar e monitorar a efetivação de tão importante política pública.

Em verdade, há apenas uma referência (indireta) ao acolhimento permanente, quando, ao tratar do acolhimento temporário, assim prevê o artigo 8ㅇ, § 4으, do Decreto 7.053/09: "§ 4으 A rede de acolhimento temporário existente deve ser reestruturada e ampliada para incentivar sua utilização pelas pessoas em situação de rua, inclusive pela sua articulação com programas de moradia popular promovidos pelos Governos Federal, estaduais, municipais e do Distrito Federal (grifos aditados)".

Logo, embora o texto refira-se diretamente à restruturação da rede de acolhimento temporário, essa pode ser uma alternativa permanente à moradia na rua, com a destinação de parte das unidades de moradia popular para viabilizar um programa de acolhimento permanente.

\section{ACOLHIMENTO PERMANENTE: BENEFÍCIOS E PERSPECTIVAS}

Inicialmente, registre-se que, muitas vezes, uma política de acolhimento temporário é suficiente para restabelecer a condição de dignidade do indivíduo, vitimado por descontrole momentâneo, decorrente de problemas de saúde, desemprego ou desarticulação familiar. Dentro desse grupo populacional, contudo, há uma parcela de indivíduos que vive situação de rua crônica. Usualmente são indivíduos com uma idade mais avançada, dependentes químicos ou com severos problemas mentais, que já moram na rua há mais de dois anos.

Nesses casos mais graves, a elevada vulnerabilidade social, o abandono aos tratamentos lineares tradicionais e os altos custos sistêmicos das iniciativas, exigem uma abordagem diferenciada que se adeque às peculiaridades do caso, até porque muitos desses indivíduos evitam os abrigos perante a ausência da liberdade de que gozam quando estão em situação de rua (43,9\% apontaram a falta de liberdade como motivo para não se recolher em albergues).

A alteração dessa abordagem linear de tratamento para adoção de um modelo em que se assegura uma segurança habitacional permanente, sem condicionamento a tratamento e se assegurando a liberdade de escolha aos beneficiários, constitui uma revolução, uma mudança de paradigma kuhniana, como definiu Davidson (2006, p. 126).

\subsection{Experiências internacionais. Housing First}

Housing First é uma iniciativa pioneira introduzida por Sam Tsemberis, no final da década de 80 do século 20, ao testemunhar pessoalmente a falência do modelo tradicional no combate à vulnerabilidade das pessoas em situação de rua.

Nessa época, o professor da Universidade de Columbia trabalhava em um serviço de emergência móvel de um Hospital em Nova York, e testemunhou, em primeira mão, que os modelos assistenciais até então instituídos, além de não resolverem de forma definitiva o problema, contavam com recorrente recidiva (BLANCO, 2016).

Além de amplamente aplicada nos EUA e Canadá, a estratégia do programa começou a ser adotada na França, Dinamarca, Finlândia, Irlanda, Holanda e Suécia. 
Para se ter uma ideia do sucesso da abordagem, após a adoção do programa a Finlândia conseguiu diminuir em 40\% sua população de rua em apenas uma década (POHJANPALO, 2019).

A expressão housing first fora inicialmente utilizada, em 1999, pela National Alliance to End Homeless, podendo ser definida como uma alocação de pessoas em situação de rua em moradias permanentes, como medida inicial do tratamento, com a disponibilidade de serviços de suporte médico-assistenciais, mas sem obrigatoriedade da referida pessoa de se submeter aos mesmos como condicionante para o recebimento da moradia (KERTESZ et al., 2009, p. 498-501). Pode-se conceber que não há apenas uma sistemática, uma vez que inúmeros modelos podem ser adotados com base na diretiva referida. Há três tipos genéricos distintos do serviço (PLEACE' 2012, p. 3).

O primeiro sistema fora originalmente desenvolvido, em Nova York, pela organização Pathways, sendo conhecido por Pathways Housing First (PHF). Ele é destinado para as pessoas em situação de rua de maior vulnerabilidade social (doentes mentais severos, dependentes químicos, etc.). As pessoas são alocadas em unidades individuais sem uma vinculação específica (concentração). $O$ tratamento associado é prestado por meio de profissionais integrantes de equipe móvel, que visita os beneficiados em suas residências ou em locais previamente combinados. A submissão ao tratamento e a abstinência são facultativas.

Um dos traços característicos desse sistema é a de não concentrar os indivíduos em localidades específicas, posto que o objetivo do programa é promover a reinserção social da pessoa em situação de rua. Logo, o beneficiário é alocado em uma unidade habitacional alugada, tendo o PHF como fiador. Além do efeito ressocializador e de se contemplar o direito de moradia como ele efetivamente é - um direito humano básico -, esse sistema evita as chagas sociais e o preconceito relacionados à preconcepção que as pessoas têm de abrigos, ao evitar uma grande concentração de beneficiários em um único local. A reinserção dos beneficiários, de forma separada, afasta estigmas e promove a reinclusão social.

O segundo sistema chama-se Communal Housing First (CHF). Ele também destina-se a pessoas em situação de rua em grave vulnerabilidade social. Não fornece moradias isoladas, e sim um sistema comunitário, no qual todos os beneficiados residem no mesmo imóvel (unidade residencial ou prédio), enquanto o tratamento é oferecido no próprio local ou em localidade muito próxima. Tratamento e abstinência igualmente não são obrigatórios.

O terceiro grande sistema é o Housing First "Light" (HFL). Não se restringe a beneficiários em grave situação de vulnerabilidade, abrangendo pessoas na iminência de ficarem ao relento, ou famílias e indivíduos jovens já em situação de rua. Não oferece tratamento médico direto.

O que caracteriza todos os sistemas citados como integrantes do programa Housing First é que se assegura, de imediato, sem condicionantes, uma moradia permanente para indivíduos em situação de rua (seja individual, seja comunitário), sem a obrigatoriedade de submissão a tratamento médico/psiquiátrico ou tratamento para a dependência química.

A ideia já transparece no próprio nome do programa (housing first), no qual se destaca que o primeiro passo primordial para se resgatar a dignidade do indivíduo é se lhe assegurar o direito humano à moradia adequada e permanente, sem riscos imediatos de despejo/desalocação.

A grande mudança obtida pelos programas que adotam tal metodologia consiste em se afastar do modelo linear tradicional de abordagem do problema, que exigia inicialmente (e como condicionantes para a continuidade do atendimento) o tratamento das condições que afligiam as pessoas em situação de rua - tratamento médico-psiquiátrico e/ou tratamento para a dependência química - para possibilitar a passagem progressiva para a moradia permanente.

No caso do housing first, há uma dissociação entre a concessão da moradia permanente e a exigência de tratamento. Essa abordagem linear anterior era composta de etapas, verificando-se que tais serviços eram etapas necessárias para se conseguir a moradia permanente. Esse modelo não alcançava os objetivos, posto que os usuários eventualmente abandonavam ou eram expulsos do programa (PLEACE, 2018, p. 4).

Esses programas pioneiros, chamados de LRT (linear residential treatment) ou modelo de escadas (staircase model), destinavam-se a tratar pessoas em situação de rua com problemas mentais severos e/ou grave dependência alcoólica e de drogas, e era idealizado em degraus, que se iniciava com moradias comunitárias, 
progredindo para ambientes mais próximos de um lar, terminando por conferir moradia independente. Essas etapas, entretanto, exigiam abstinência na utilização de drogas e álcool, além de submissão obrigatória a tratamentos clínicos e atingimento de metas por parte dos beneficiados.

A grande crítica a esses programas é exatamente a alta incidência de seu abandono por parte dos beneficiários (PLEACE, 2018, p. 2-3). Como a moradia permanente constitui a última etapa do programa, qualquer recaída no curso deste excluía o beneficiário e o devolvia à situação de rua. Em verdade, enquanto não vencidas todas as etapas, com êxito, o indivíduo beneficiado, já vitimado pelas graves condições pessoais, também não tinha segurança habitacional, uma vez que este consistia no último objetivo a ser atingido (a moradia é conquistada).

Além do insucesso da abordagem linear, com elevado grau de reincidência no uso abusivo de entorpecentes e álcool e abandono do tratamento clínico para doenças mentais, também se verifica um elevado custo fiscal.

Os indivíduos que padecem dessas enfermidades e condições consomem uma quantia desproporcional de recursos públicos - em abrigos, hospitais, hospícios e prisões -, que alguns estudiosos estimavam que ultrapassava a metade dos recursos alocados para todos os serviços de emergência e abrigos (DAVIDSON, 2006, p. 127), embora estudos demonstrem que eles representam apenas $20 \%$ dos usuários de abrigos. Estudos mostraram que o custo assistencial anual combinado por pessoa era de US\$ 40.500 em Nova York (LY; LATIMER, 2015, p. 476).

Parece intuitivo concluir que o pagamento integral ou parcial (subsídios) de alugueres a pessoas em situação de rua acarreta alto custo, o que é verdade. O alto custo dessas locações, associado a políticas de austeridade fiscal pós-crise de 2008 , tem constituído barreiras ao financiamento de moradias e serviços para pessoas em situação de rua (DOBSON, 2018, p. 311).

Uma análise mais ampla do fenômeno, contudo, demonstra que o aumento no custo da habitação é compensado pela diminuição dos custos médico-hospitalares e correlatos, embora os estudos não sejam conclusivos pela disparidade de parâmetros (LY; LATIMER, 2015, p. 486).

Logo, quando se comparam os custos de pacientes com severos distúrbios psiquiátricos e/ou grave quadro de dependência química, os resultados direcionam para uma efetiva compensação de custos. A organização Pathways apresentou um quadro comparativo dos custos diários da execução do programa, expondo os seguintes valores: US\$ 57 por noite no PHF; US\$ 73 em abrigos emergenciais; US\$ 164 na cadeia; US\$ 519 em Emergência de Hospital; US\$ 1.185 em Hospital Psiquiátrico (PLEACE, 2012, p. 58).

Assim, a alocação permanente de um indivíduo em grave situação de vulnerabilidade, no final das contas, reverte-se em grande economia de recursos. Ao analisar o caso de Murray, um veterano de guerra com graves distúrbios mentais, Padgett ressalta que esse indivíduo, em particular, pode acumular mais de 80 internações anuais em Emergências de Hospitais (PADGETT, 2015, p. 58).

Logo, uma alocação permanente reduz os graves riscos associados à situação de rua, agravando doenças e distúrbios já presentes (o que acarreta encarceramento e/ou internação, com elevados custos associados), com efetiva redução de danos, além de viabilizar tratamento efetivo (caso o beneficiário assim deseje, respeitando seu direito de escolha).

Isso verifica-se porque a habitação permanente produz inúmeros efeitos nos indivíduos, devolvendo- Ihes (em parte) a dignidade perdida e o senso de responsabilidade, além da alocação em moradia adequada, afastando-o da situação de rua. A qualidade da moradia e da vizinhança refletem-se, inclusive, na saúde dos indivíduos.

Há estudos que associam elementos ambientais da habitação e problemas de saúde, a exemplo de insuficiência de iluminação solar associada à depressão e níveis de ruído associados a distúrbios psicológicos, e da quantidade de estabelecimentos que comercializam bebidas alcoólicas na vizinhança e os índices de criminalidade (ADAIR et al., 2016, p. 683).

Logo, a abordagem tradicional peca pela pouca efetividade (dada a recidiva e a obrigatoriedade de submissão a tratamento/abstinência) e pelo alto custo sistêmico. Esse custo-benefício é muito maior quando se compara o tratamento linear e a abordagem do HF em indivíduos sujeitos à grave vulnerabilidade (distúrbios psiquiátricos e dependência química). 
Inúmeros modelos adequados a cada localidade e peculiaridade têm sido desenvolvidos. O modelo espanhol iniciou-se em 2014 por meio da Fundação Rais (Red de Apoyo a la Integración Sociolaboral), que instituiu o programa em 38 quadras nas cidades de Madrid, Málaga e Barcelona (VILARRODONA, 2016, p. 64), mas que já conta, atualmente, com inúmeras outras iniciativas, em incontáveis cidades espanholas.

A introdução do modelo na Espanha gerou muitas expectativas para os diferentes atores envolvidos, porque os resultados mostram que este enfoque pode ser mais eficaz e menos custoso para obter a incorporação social de pessoas em grave vulnerabilidade (ESTANY et al., 2016, p. 8).

Outros países europeus adotaram a metodologia do housing first, como relata Marian Martínez González (GONZALEZ, 2017, p. 175), com resultados encorajadores. Na Áustria obteve-se um índice de comprometimento na ordem de $98,3 \%$ dos participantes. Na Bélgica destaca-se a ausência de centralização, com cada organização fornecendo diferentes serviços às pessoas em situação de rua, de acordo com as peculiaridades. A Dinamarca aproxima-se do modelo Canadense e Francês (Chez Soi), com adoção dos modelos de tratamento Intensive Case Management (ICM - que vincula o tratamento a outros serviços de saúde, assistência e trabalho, atuando especialmente na fase inicial da situação de rua) e Assertive Community Treatment (ACT equipe multidisciplinar que oferece tratamento direto a indivíduos de elevada necessidade e vulnerabilidade, como problema de saúde física e mental e dependência química). A Finlândia, como já referido, obteve uma diminuição notável na moradia em situação de rua com a adoção do programa.

Conclui Gonzáles (2017, p. 184) que a França realizou um dos maiores testes do modelo Housing First, que foi feito na Europa. O programa batizado de Un Chez-Soi d'abord testou o modelo em quatro cidades Lille, Paris, Toulouse e Marselha, de 2011 a 2016 - e foi liderado nacionalmente pelo DIHAL (Departamento interministerial responsável pela estratégia nacional pela falta de moradia). Os departamentos de saúde, habitação e assistência social do governo francês participam do Programa. Todos os serviços da Housing First possuem comitês de gestão em âmbito local, geralmente constituídos por todas as organizações participantes (saúde, assistência social, bem-estar social), e há um comitê de direção nacional. As taxas de comprometimento com o programa foram superiores a $80 \%$.

Como percebe-se, as inúmeras experiências nos mais diferentes países têm demonstrado êxitos ressocializadores e compensação financeira no enfrentamento da situação crônica de falta de moradia.

\subsection{Reintegração social e comunitária facilitada}

Com o estabelecimento de uma política de segurança habitacional para os indivíduos em situação de rua, sua reintegração social e comunitária constitui uma etapa razoavelmente simples do processo de resgate de sua dignidade humana intrínseca.

A mera situação de segurança habitacional, contudo, não é suficiente para uma efetiva reinserção no mercado de trabalho formal.

Diferentemente do que o senso comum pressupõe, os dados estatísticos desse segmento populacional impressionam. Segundo dados do governo federal, $70,9 \%$ desses indivíduos exercem atividade remunerada (catador de materiais recicláveis (27,5\%); flanelinhas (14,1\%); construção civil $(6,3 \%)$; limpeza $(4,2 \%)$ etc.). Apenas uma parcela pequena pede dinheiro como principal meio de sobrevivência (15,7\%). Além disso, $74 \%$ dos pesquisados sabem ler e escrever (BRASIL, 2008).

Como observa-se, são atividades informais que imperam como meio de sustento dessa parcela populacional. Logo, uma paulatina (re)inserção no mercado de trabalho formal, como parte de uma política integrada e interdisciplinar, pode favorecer uma melhor readequação do indivíduo.

A integração social exige mais do que a concessão de segurança habitacional. A moradia pode ser segura e autossustentável, mas a ausência de laços familiares e de amizade, pouca inclusão da comunidade circundante, saúde precária e recursos econômicos escassos, ainda podem continuar depois que a experiência física da ausência de lar terminar (PLEACE, 2018, p. 59).

Logo, a simples concessão de uma moradia permanente propicia inúmeros benefícios relacionados à saúde física e mental de tais indivíduos, embora ainda não seja suficiente para se lhes propiciar uma efetiva reinserção no mercado de trabalho formal, devendo-se utilizar, nesses casos, serviços de reabilitação/readequação laboral prestados pela rede assistencial. 


\subsection{Segurança habitacional para pessoas em situação de rua e uma proposta para o Brasil}

Como já estabelecido anteriormente, tanto interna (com jaze constitucional) quanto externamente, o direito à moradia/habitação é um direito humano fundamental, que tem influência na saúde física e mental do indivíduo.

Assim, a rualização constitui uma violação gravíssima da dignidade da pessoa humana, enquanto a alocação em moradia adequada produz no indivíduo uma segurança ontológica - “... um senso de ordem, confiança, continuidade e segurança (Giddens, 1990; Dupuis e Thorns, 1998)", constituindo uma profunda necessidade psicológica (MUIR, 2018, p. 32).

Observa-se que há melhorias sensíveis na concessão de segurança habitacional a pessoas em situação de rua, uma vez que a taxa de mortalidade prematura entre moradores de rua crônicos é três vezes superior à da população em geral (WHITTAKER, 2017, p. 306).

Logo, o Brasil deveria seguir a tendência atual de utilização de uma variação do modelo Housing First para tentar debelar a grave situação de parcela da população de rua em situação crônica, que se adequa aos ditames suprapropostos.

Parece que o sistema Communal Housing First (CHF) seria o mais adequado para a realidade brasileira, considerando nossas peculiaridades.

Inicialmente, como demonstrado, enfrenta-se no Brasil um elevado deficit habitacional. Se, então, não há moradia suficiente disponível para atender à população de forma geral, fica mais complicado (e mesmo custoso) adotar o sistema de subsídios no custeio de alugueres para a população em situação de rua crônica.

Verifica-se, ainda, parcos recursos financeiros diante da grave crise fiscal vivenciada nos últimos anos, o que exige eficiência no gasto público. Logo, a remuneração e deslocamento de equipes interdisciplinares entre inúmeras unidades habitacionais seria elevado, quase inviabilizando a manutenção do programa, sendo muito menos custoso deslocar a equipe para local específico, podendo tratar dezenas de pessoas em situação de risco.

Observa-se, ainda, a existência de dezenas de milhares de imóveis públicos abandonados; apenas do governo federal contabilizam-se mais de 10.000 imóveis abandonados, o que se repete nas inúmeras esferas de governo (estaduais e municipais) (FONSECA, 2018).

Assim, a adoção de prédios governamentais já desafetados (uma vez que se encontram abandonados, sem utilização, desatendendo à sua função social) como prédios comunitários para alocação permanente de indivíduos em situação crônica de rua, com a possibilidade de concentração da prestação de atendimento médico-psiquiátrico (por meio de equipes multidisciplinares) e de prestação de serviços facultativos (reabilitação profissional, benefícios assistenciais como o bolsa-família e Benefício de Prestação Continuada (BPC) para indivíduos com deficiência), possibilitaria desenvolver o programa com um custo fiscal reduzido, compensando-se os gastos com o Sistema Único de Saúde e Prisional que envolvem tais indivíduos, além de resolver um grave problema de destinação de bens públicos abandonados.

\section{CONCLUSÃO}

O Direito à Moradia adequada constitui um direito humano e fundamental, de natureza social, de salutar importância, por viabilizar o próprio exercício dos demais direitos. Nesse contexto, viabilizar o efetivo exercício de tal direito, criando as políticas públicas necessárias a efetivar a disponibilização de moradia a todos, constitui uma das principais aspirações dos gestores contemporâneos.

Tal direito pode ser definido como a posse exclusiva, durante um razoável período de tempo, de espaço determinado, no qual se tenha proteção contra intempéries, assegurando-se a intimidade do indivíduo além da possibilidade de prática dos atos elementares da vida humana, tais como alimentação, repouso, higiene, reprodução e comunhão.

A moradia deve ser adequada, o que exige segurança legal da posse, disponibilidade de serviços, materiais, facilidades e infraestrutura, custo acessível, habitabilidade, acessibilidade, localização (proximidade de serviços públicos essenciais e opções de trabalho e lazer) e adequação cultural. 
Tal direito é previsto em inúmeros instrumentos internacionais, além de constar como objetivo da Agenda 2030 da ONU. No âmbito interno, fora incluído pela EC no 26/2000, que alterou a redação do artigo 6ㅇda $\mathrm{CF}$, incluindo o direito à moradia dentre o rol de direitos fundamentais sociais.

Se a moradia adequada constitui direito social fundamental, a condição das pessoas em situação de rua assume uma gravidade inconteste. Segundo definição normativa, trata-se de grupo populacional heterogêneo que possui em comum a pobreza extrema, os vínculos familiares interrompidos ou fragilizados e a inexistência de moradia convencional regular, e que utiliza os logradouros públicos e as áreas degradadas como espaço de moradia e de sustento, de forma temporária ou permanente, bem como as unidades de acolhimento para pernoite temporário ou como moradia provisória.

Estima-se que existiam pouco mais de cem mil pessoas em situação de rua no Brasil (dados e análise de 2015), e os abrigos existentes são insuficientes para acolher tais indivíduos, ainda mais quando se verifica um elevado déficit habitacional no país.

As soluções normativas governamentais para debelar o problema são insuficientes, até porque se limitam à prestação de serviços provisórios e acolhimento temporário, sem combater a raiz do problema, que é ainda mais grave quando se observa um grupo específico dentre aqueles em situação de rua que experimenta uma situação crônica de vulnerabilidade (extenso período de rualização, idade avançada, dependência química, graves problemas mentais, podendo ou não estar associados).

Nesses casos mais graves, o alto custo dos serviços alternativos (inclusive com internações psiquiátricas e encarceramento) e o elevado grau de insucesso da abordagem linear tradicional (dada a recidiva), conduziu a uma quebra de paradigma, com a adoção de um modelo chamado de Housing First.

Adotado inicialmente nos EUA, por Sam Tsemberis, o Programa se afasta da abordagem tradicional, dissociando imposição de tratamento da segurança habitacional.

Nesse modelo, que é adotado com inúmeras variações, a fim de se adequar às peculiaridades locais, o primeiro passo consiste no oferecimento de moradia permanente para o indivíduo, com oferta de serviços correlatos e tratamento, mas sem a obrigatoriedade de o indivíduo beneficiado se submeter a tais prestações como condição para permanência na habitação. Sequer exige-se abstinência. Respeita-se a liberdade do indivíduo com a redução de riscos associados à rualização, que acabam compensados financeiramente pela redução de gastos com saúde e assistência social. Inúmeros países têm adotado tais sistemas, com resultados encorajadores.

Como passo subsequente da segurança habitacional, tem-se a reintegração social e a melhoria da saúde dos indivíduos beneficiados, como solução permanente para a reinserção socioambiental de indivíduos até então excluídos do convívio social, alijados de uma dignidade mínima.

No caso do Brasil, dentre os inúmeros modelos adotados pelo mundo, aquele que mais se adequa às nossas peculiaridades é o Communal Housing First (CHF), por conciliar baixo custo fiscal com eficiência na alocação de serviços públicos, além de não agravar nosso déficit habitacional e dar uma destinação social às dezenas de milhares de imóveis públicos abandonados.

\section{REFERÊNCIAS}

ADAIR, Carol I. et al. Housing Quality in a Randomized Controlled Trial of Housing First for Homeless Individuals with Mental Illness: Correlates and Associations with Outcomes. Journal of Urban Health: Bulletin of the New York Academy of Medicine, v. 93, n. 4, 2016.

BLANCO, Silvia. O método para tirar milhares de "sem-tetos" da rua - um psicólogo radicado nos Estados Unidos criou um modelo para tirar milhares de pessoas da rua. Disponível em: https://brasil.elpais.com/brasil/2016/11/11/economia/1478889909_914418.html. Acesso em: 20 ago. 2019.

BOBBIO, Noberto. A era dos direitos. 2. ed. São Paulo: Elsevier, 2004.

BRASIL. Decreto no 50.215, de 28 de janeiro de 1961. Promulga a Convenção relativa ao Estatuto dos Refugiados, concluída em Genebra, em 28 de julho de 1951.. Disponível em: http://www.planalto.gov.br/ccivil_03/decreto/1950-1969/D50215.htm. Acesso em: 24 fev. 2020.

BRASIL. Decreto no 99.710, de 21 de novembro de 1990. Promulga a Convenção sobre os Direitos da Criança. Disponível em: http://www.planalto.gov.br/ccivil_03/decreto/1990-1994/d99710.htm. Acesso em: 24 fev. 2020. 
BRASIL. Decreto no 4.377, de 13 de setembro de 2002. Promulga a Convenção sobre a Eliminação de Todas as Formas de Discriminação contra a Mulher, de 1979, e revoga o Decreto no 89.460, de 20 de março de 1984. Disponível em: http://www.planalto.gov.br/ccivil_03/decreto/2002/D4377.htm. Acesso em: 24 fev. 2020.

BRASIL. Decreto no 591, de 6 de julho de 1992. Atos Internacionais. Pacto Internacional sobre Direitos Econômicos, Sociais e Culturais. Promulgação. Disponível em: http://www.planalto.gov.br/ccivil_03/decreto/1990-1994/d0591.htm. Acesso em: 24 fev. 2020. Acesso em: 5 jan. 2020.

BRASIL. Decreto no 7.053, de 23 de dezembro de 2009, que instituiu a Política Nacional para a população em situação de rua. 2007. Disponível em: http://www.planalto.gov.br/ccivil_03/_ato2007-2010/2009/decreto/d7053.htm. Acesso em: 20 fev. 2020.

BRASIL. Política Nacional para Inclusão Social da População em Situação de Rua. 2008. Disponível em: http://www.mpsp. $\mathrm{mp} . \mathrm{br} /$ portal/page/portal/cao_civel/acoes_afirmativas/inclusaooutros/aa_diversos/Pol.Nacional-Morad.Rua.pdf.

DAVIDSON, Nestor M. "Housing First" for the chronically Homeless: Chalenges of a new service model. Journal of Affordable Housing, University of Colorado Law School, v. 15, n. 2, p. 125-136, 2006.

DOBSON, Rachael. Policy responses to "rough sleepers": Opportunities and barriers for homeless adults in England. Critical Social Policy, v. 39, 2, p. 309-321, 2018.

DUARTE, Hugo Garcez, Apoliézer. Dignidade da pessoa humana e direito à moradia: reflexões frente ao conceito de Estado Democrático de Direito. In: Revista Jus Navigandi, Teresina, 2015. Disponível em: Acesso em: 20 ago. 2018.

ESTANY, Marta Llobet et al. Interrogantes sobre la implantación del modelo Housing First en el contexto español. Trabajo presentado al Grupo de Trabajo 4.3 "Debatiendo sobre la evaluación de políticas sociales: enfoque, indicadores y prácticas". CONGRESO RED ESPAÑOLA DE POLITICAS SOCIALES, 6., 2016. Sevilla, 16 e 17 feb. 2016.

FONSECA, Bruno; FERRARI, Caroline. Milhares de imóveis da União estão vagos para uso. 21 de junho de 2018. Disponível em: https://apublica.org/2018/06/milhares-de-imoveis-da-uniao-estao-vagos-para-uso/. Acesso em: 20 jan. 2020.

GONZALEZ, Marian Martínez. El modelo housing first para las personas sin hogar en Bizkaia. Fundacion UNED, 2017. p. 175 et seq.

IPEA. Pesquisa estima que o Brasil tem 101 mil moradores de rua. Disponível em: http://www.ipea.gov.br/portal/index.php?option=com_content\&view=article\&id=29303. Acesso em: 28 set. 2019.

JÚNIOR, Luciano Roberto Gulart Cabral; COSTA, José Ricardo Caetano. Barreiras à cidadania nas políticas sociais para a população em situação de rua. Rev. Bras. Polít. Públicas, on-line, Brasília, v. 6, n. 2, p. 236-249, 2016.

KERTESZ, Stefan G. et al. Housing First for Homeless Persons with Active Addiction: Are We Overreaching? The Milbank Quartely, v. 87, n. 2, p. 495-534, 2009.

LY, Angela; LATIMER, Eric. Housing First Impact on Costs and Associated Cost Offsets: A Review of the Literature. The Canadian Journal of Psychiatry, v. 60, n. 11, Nov. 2015.

MAZZUOLI, Valério de Oliveira. Curso de Direitos Humanos. 4. ed. Editora Método, 2017. E-book do Kindle.

MUIR, Kristy et al. Amplify Insights: Housing Affordability \& Homelessness. Sydney, UNSW: Centre for Social Impact, 2018. p. 32. NATALINO, Marco Antonio Carvalho. Estimativa da população em situação de rua no Brasil. Texto para discussão do Instituto de Pesquisa Econômica Aplicada. Brasília: Ipea, 2016.

NOLASCO, Loreci Gottschalk. Direito fundamental social à moradia: aplicação, limites e a responsabilidade do Estado brasileiro. Brasília. Disponível em: http://sisnet.aduaneiras.com.br/lex/doutrinas/arquivos/100807.pdf. Acesso em: 20 ago. 2018.

OFFICE OF THE UNITED NATIONS COMMITTEE ON ECONOMIC, SOCIAL AND CULTURAL RIGHTS. UN Habitat. The right to adequate housing. Geneva, Switzerland, Fact Sheet n. 21, Rev. 1, 2014.

ONU. Agenda 2030 da ONU. Disponível em: https://nacoesunidas.org/pos2015/agenda2030/. Acesso em: 24 fev. 2020.

PADGETT, Deborah. Housing First. Oxford: Oxford University Press, 2015. E-book do Kindle.

PLEACE, Nicholas. Housing First. European Observatory on Homelessness. [S.I.]: Feantsa, 2012.

PLEACE, Nicholas. Using Housing First in integrated homeless strategies - a review of the evidence. University of York, 2018. Disponível em: https://www.mungos.org/publication/using-housing-first-integrated-homelessness-strategies/. Acesso em: 13 fev. 2020.

PLEACE, Nicholas; BRETHERTON, Joanne. Is Work an Answer to Homelessness? Evaluating an Employment Programme for Homeless Adults. European Journal of Homelessness, v. 13, n. 1, p. 59-83, 2018.

PLEACE, Nicholas et al. Will Paradigm Drift Stop Housing First from EndingHomelessness? Categorising and Critically Assessingthe Housing First Movement from a Social Policy Perspective. University of York, 2012. Disponível em: https://www.academia. edu/2197784/Will_Paradigm_Drift_Stop_Housing_First_from_Ending_Homelessness_Categorising_and_Critically_Assessing_ the_Housing_First_Movement_from_a_Social_Policy_Perspective. Acesso em: 10 jan. 2020.

POHJANPALO, Katy. American Idea Inspires Finland to Slash Homelessness by 40\%. 2019. Disponível em: https://www.bloomberg.com/news/articles/2019-07-19/american-idea-inspires-finland-to-slash-homelessness-by-40. Acesso em: 10 jan. 2020. 
RAMOS, André Ramos de. Curso de direitos humanos. 5. ed. São Paulo: Saraiva, 2018.

RANGEL, Helano Márcio Vieira, SILVA, Jacilene Vieira da. O direito fundamental à moradia como mínimo existencial, e a sua efetivação à luz do estatuto da cidade. Revista Veredas do Direito, Belo Horizonte, v. 6, n. 12, p. 57-78, jul./dez. 2009.

SARLET, Ingo Wolfgang. Dignidade da pessoa humana e direitos fundamentais: na Constituição Federal de 1988. [S.I.]: Livraria do Advogado Editora. E-book Kindle.

SILVA, Rosimeire Barbosa da; COSTA, Alderon Pereira da. Direitos humanos da população em situação de rua? Paradoxos e aproximações à uma vida digna. Revista Direitos Humanos e Democracia, ljuí: Editora Unijuí, ano 3, n. 6, p. 117-135, jul./dez. 2015.

UNITED NATIONS. Comentário Geral n. 4 do Comitê sobre os Direitos Econômicos, Sociais e Culturais (Sexta sessão, 1991) [UN doc E/1992/23]. Moradia e Direitos Humanos. Disponível em: http://www.dhnet.org.br/direitos/sos/moradia/trabalhohabitacaopronto.html\#8.

VILAS BOAS, Bruno; CONCEIÇÃO, Ana. Déficit de Moradias no país já chega a 7,7 milhões. 3 de maio de 2018. Disponível em https://www.valor.com.br/brasil/5498629/deficit-de-moradias-no-pais-ja-chega-77-milhoes. Acesso em: 28 set. 2019.

VILARRODONA, Joan Uribe. Housing First: Un modelo de cambio. Definición, actualidad, límites y retos. Revista de Treball Social, Col-Legi Oficial de Treball Social de Catalunya, n. 209, dic. 2016, p. 57-70.

VILELA, Flávia. Número de pessoas em situação de rua aumenta mais de 150\% em 3 anos no Rio. 2017. Disponível em: http://agenciabrasil.ebc.com.br/geral/noticia/2017-06/numero-de-pessoas-em-situacao-de-rua-aumenta-mais-de-150-em3-anos-no-rio. Acesso em: 20 ago. 2019.

WHITTAKER, Elizabeth et al. First examination of varying health outcomes of the chronically homeless according to Housing First configuration. Australian ans New Zeland. Jornal of Public Health, v. 41, n. 3, p. 306-308, 2017. 